\title{
O RELATO DE UM EXPERIÊNCIA DE CONSTRUÇÃO DE NOVA METODOLOGIA PARA O CURSO DE ADMINISTRAÇÃO
}

\author{
CURITIBA/PR ABRIL/2018 \\ $\begin{array}{cc}\text { Vanessa Estela Kotovicz Rolon } & \text { - UNINTER - vanessa.ro@uninter.com } \\ \text { Elizeu Barroso Alves } & \text { - UNINTER - elizeu.a@uninter.com } \\ \text { Ademir Moreira Bueno } & \text { - UNINTER - ademir.b@uninter.com } \\ \text { Aline Mara Gumz Eberspacher } & \text { - UNINTER - aline.e@uninter.com }\end{array}$
}

Tipo: Relato de Experiência Inovadora (EI)

Categoria: Métodos e Tecnologias

Setor Educacional: EDUCAÇÃO SUPERIOR

\begin{abstract}
RESUMO
Este artigo tem por objetivo analisar a interdisciplinaridade na implantação de nova metodologia de ensino-aprendizagem no curso de Administração de uma Instituição de Ensino Superior localizada na cidade de Curitiba, e avaliar como se processou a aprendizagem como prática dos envolvidos. A pesquisa adotou abordagem qualitativa, com delineamento descritivo e estudo de caso, seguindo corte seccional, realizando uma etnografia e operacionalizada por meio de entrevistas, observação participante e documentos. Para análise dessa pesquisa, utilizamos como base teórica, a prática, considerada de forma processual, ou seja, como uma ação social, possibilitando que haja aprendizagem organizacional, podendo haver a formação de uma comunidade de prática. Evidenciamos neste que, a criação e o desenvolvimento da interdisciplinaridade ocorreu por meio da construção coletiva da matriz de conteúdo das disciplinas, bem como, por meio da elaboração das rotas de aprendizagem pelos professores envolvidos no processo, o que possibilitou o desenvolvimento da interdisciplinaridade durante a construção do projeto e sua execução.
\end{abstract}

Palavras-chave: Interdisciplinaridade; Metodologias Ativas; Competências; Aprendizagem.

\section{AGRADECIMENTOS}

*ELIZEU BARROSO ALVES É BOLSISTA DO PROSUP-CAPES 


\section{CONSIDERAÇÕES INICIAIS}

Esse estudo teve como objetivo: compreender e descrever como uma Instituição de Ensino Superior (IES), localizada na cidade de Curitiba/PR, criou e desenvolveu a interdisciplinaridade no currículo do curso de Administração visando adaptar-se ao atual contexto histórico-social de nosso tempo, que demanda novas competências ao egresso deste curso, alterando assim sua prática de ensino. Cabe ressaltar que o curso de Administração é o curso com a maior procura no Brasil, onde em 2016, segundo o Censo da Educação Superior do Ministério da Educação (MEC), o curso de Administração foi o maior em número de matrículas 710.778 e em número de ingressantes 257.938, ficando em terceiro no número de concluintes 87.050 (INEP, 2016).

A escolha do objeto de pesquisa se deu em consideração as demandas estabelecidas às IES, que são: (a) atender às prerrogativas do Ministério da Educação (MEC), por meio das Diretrizes Curriculares Nacionais (DCNs); (b) formar profissionais que atendam ao perfil que o mercado de trabalho solicita e aos anseios da sociedade para que o desenvolvimento econômico ocorra de forma sustentável, pautado nos princípios de ética e de responsabilidade social.

Essas exigências impostas às IES, atendem a necessidade do mercado, que necessita de um novo perfil do administrador e requer uma formação interdisciplinar. Por isso nos faz sentido a compreensão de como a IES, foco deste estudo, propôs a reestruturação do currículo do curso de Administração de forma que as disciplinas fossem ofertadas em módulos, por meio de um eixo temático, sendo dessa forma interdisciplinares.

O método para apreensão dessa reestruturação se deu pela análise prática dos docentes em reuniões, por meio de observação participante, entre 2015 e 2017, tendo como metodologia utilizada a etnografia.

\section{O ENSINO DE ADMINISTRAÇÃO: A REFLEXÃO DA NECESSIDADE DE 'MOVIMENTO'}

Partimos da premissa de que o estudante deve ter uma formação integral, ou seja, não somente ter conhecimento sobre as ferramentas técnicas de uma profissão, mas também a formação em valores éticos e morais. Premissa essa que vai ao encontro do artigo primeiro da Lei 9.394 de 20 de dezembro de 1996 - Lei das Diretrizes Básicas da Educação (LDB) - que definiu e regularizou o sistema de educação brasileiro. 
Art. 1․ A educação abrange os processos formativos que se desenvolvem na vida familiar, na convivência humana, no trabalho, nas instituições de ensino e pesquisa, nos movimentos sociais e organizações da sociedade civil e nas manifestações culturais (BRASIL, 1996, grifo nosso).

Assim, para atender o distinto artigo, o MEC, institui resoluções que instituem as DCN, bem como pareceres que são as referências para tais diretrizes. No caso do curso de Administração temos a Resolução n 4, de 13/07/2005 e o Parecer CNE/CES 67, de 11/03/2003. Com isso, vejamos os itens referenciais dos campos interligados de formação curriculares para o curso, em seu artigo $5^{\circ}$

Art. 50 Os cursos de graduação em Administração deverão contemplar, em I Conteúdos de Formação Básica: relacionados com estudos antropológicos, sociológicos, filosóficos, psicológicos, ético-profissionais, políticos, comportamentais, econômicos e contábeis, bem como os relacionados com as tecnologias da comunicação e da informação e das ciências jurídicas";

II - Conteúdos de Formação Profissional: relacionados com as áreas específicas, envolvendo teorias da administração e das organizações e a administração de recursos humanos, mercado e marketing, materiais, produção e logística, financeira e orçamentária, sistemas de informações, planejamento estratégico e serviços;

III - Conteúdos de Estudos Quantitativos e suas Tecnologias: abrangendo pesquisa operacional, teoria dos jogos, modelos matemáticos e estatísticos e aplicação de tecnologias que contribuam para a definição e utilização de estratégias e procedimentos inerentes à administração; e

IV - Conteúdos de Formação Complementar: estudos opcionais de caráter transversal e interdisciplinar para o enriquecimento do perfil do formando. (BRASIL, 2005).

A partir da DCN, as IES que ofertam os cursos de administração elaboram suas grades curriculares, com a liberdade de ofertar as disciplinas que atendam a demanda da resolução. Porém, como herança do funcionalismo e do espírito gerencialista oriundos de seu berço estadunidense, restrito à lógica utilitarista, apresentam em sua maioria, grades curriculares no sentido do conhecimento básico para o menor, onde apenas no final do curso o egresso seria capaz de 'juntar os pontos' do seu aprendizado. Isso ocorre pela falta de interdisciplinaridade entre as disciplinas que se apresentam ao longo da grade de forma isolada, em o que podemos chamar de 'pacotes semestrais', onde a lógica de fragmentação em disciplinas, numa visão cartesiana do conhecimento 
(D’AMBROSIO, 1999).

Nessa proposta, o ensino ou melhor, as disciplinas, se aplicam em todo o território nacional, e nesse contexto De Barcellos, Do Livramento Dellagnelo e Saliés (2011, p.673) discutem uma reflexão da formação do administrador, onde apresentam que "a formação do administrador esteja ocorrendo de forma circunscrita ao paradigma dominante, deixando de abordar e, portanto, de formar para possibilidades e realidades sociais diferentes da organização empresarial”.

Nessa forma de ensino, a aprendizagem se propaga com foco no individual, onde o professor é o detentor da verdade, e o aluno o passivo no processo, é um 'a-luno', e não um estudante. Claro, que diferentemente da imersão positivista, não queremos generalizar esse fato, ao ponto de que diversas Faculdades, Centro Universitário e Universidades, bem como o mundo acadêmico vem se debruçando e refletindo nessa realidade. Como por exemplo, Assis et al (2013) que chamam a atenção para uma pedagogia crítica, onde "de vista ontológico, a pedagogia crítica parte do pressuposto de que um outro mundo é possível e de que a educação não deve ser resultado de um processo de ajuste do sujeito à realidade presente". (ASSIS et al., 2013, p.47-48). Com isso os autores chamam a atenção para a participação dos estudantes como sujeitos de sua aprendizagem, em uma visão de que esta é um processo dialógico.

Com isso, entendemos que a interdisciplinaridade entre as disciplinas sendo presente na grade curricular e a adoção de metodologias ativas em sala de aula, pode trazer bons avanços na arte de formar contemporânea, pois "o parcelamento e a compartimentação dos saberes impedem apreender o que está tecido junto" (MORIN, 2002, p.45). Destarte, partimos de que a interdisciplinaridade pode ser apresentada como "a intensidade das trocas entre os especialistas e pelo grau de interação real das disciplinas no interior de um mesmo projeto de pesquisa" (JAPIASSU, 1976, p.74). Ou seja, é a ligação entre os conhecimentos.

E por fim, há de se considerar também que aprendizagem em grupo é pouco pesquisada por teóricos da prática social, segundo Bispo (2013), o que possibilita uma contribuição para ampliação de debates acadêmicos, pois aprendizagem, geralmente é analisada sob o olhar individual, onde a visão tradicional da ciência da cognição, foca no comportamento observável dos indivíduos e suas representações mentais, enquanto numa visão da aprendizagem como fenômeno social, a aprendizagem ocorre em um contexto social, onde a cognição é partilhada socialmente entre os membros e o conhecimento existe no seio de uma comunidade. 


\section{PERCURSO METODOLÓGICO}

Para se atingir o objetivo desse estudo, que é a (i) compreensão e descrição de como uma Instituição de Ensino Superior particular, localizada na cidade de Curitiba/PR, criou e desenvolveu a interdisciplinaridade no currículo do curso de Administração, alterando assim sua prática de ensino, utilizamos como metodologia a etnografia dentro de um estudo qualitativo. Na operacionalização do levantamento de dados, que ocorreu de 2014 ao primeiro trimestre de 2016, e no acompanhamento de 20 reuniões de professores, foi utilizado um diário de campo para anotar os comportamentos, reações, discordâncias, acertos, alegrias, angustias, incertezas, frustações e negociações que os docentes realizaram, e outro diário para anotar as percepções e as reflexões feitas durante o período de tempo em que o estudo foi realizado. Também se utilizou pesquisas semiestruturadas. Tais caminhos metodológicos se deu, pois, a etnografia envolve uma descrição completa e profunda do fenômeno a ser pesquisado, assim, o pesquisador etnográfico é conhecedor da rotina, de forma a encontrar significados, que não seriam encontradas em uma pesquisa bibliográfica por exemplo.

Tal operacionalização resultou em um relatório etnográfico, com a forma de narrativa, uma longa história, que segundo Jaime Júnior (2003), tem como meta principal reproduzir para o leitor a experiência de interação e vivência do etnógrafo nessa comunidade pesquisada, pois o relatório passa a ser a descrição de como os praticantes da nova prática agem, em todas as instâncias de interação, linguagem e produção compartilhadas.

Por fim, este estudo se concentrou em observar os praticantes de uma nova prática, por implantar uma nova proposta metodológica em sala de aula

\section{APRESENTAÇÃO E ANÁLISE DOS RESULTADOS}

A pesquisa foi realizada em uma IES, localizada na cidade de Curitiba. Onde o objetivo da instituição era que no ano letivo de 2015 fosse implantada a interdisciplinaridade de disciplinas por meio do uso de novas tecnologias e novos métodos de aula, como as metodologias ativas, como por exemplo, a Flipped Classroom[1] que é uma modalidade de Blended learning[2]. Cabe lembrar que o objetivo da sala de aula invertida consiste em gastar a maior parte do tempo de aula em atividades que desenvolvam habilidades de pensamento superior, ou seja, em atividades de produção e criação de conhecimentos (HOBMEIR et al, 2017, p. 31).

Com isso, a primeira atividade dos professores era, em conjunto, elaborar o que se 
convencionou internamente na IES a se chamar de 'matriz de conteúdo'. Tal matriz era desenvolvida dentro da prática de Unidade Temática de Aprendizagem (UTA), que contém 4 disciplinas, onde um único tema é explorado por período, por exemplo, as temáticas de marketing, possibilitou a elaboração da UTA Mercadologia, contendo as seguintes disciplinas: (i) Administração de Marketing; (ii) Composto Mercadológico; (iii) Sistema de Informação de Marketing; e (iv) Comportamento do Consumidor. Ressaltando que a elaboração da UTA passa pela aprovação do Colegiado e do Núcleo Docente Estruturante (NDE) do curso.

A Matriz de conteúdo possuí as 4 disciplinas; e cada disciplina é dividida em 6 rotas de aprendizagem, onde cada rota possuí 5 temas. A nomenclatura das Rotas é a mesma para cada disciplina. Por exemplo, todas as disciplinas da UTA terá as rotas de 'aspectos introdutórios' e a 'última será o plano de marketing', e assim os alunos verão essas rotas com as lentes das disciplinas da UTA. Para a constituição da matriz de conteúdo foram convidados os professores da área, para juntos, em forma de debate, definir quais serão as temáticas de cada rota de aprendizagem. Cada Rota de aprendizagem deveria ser interdisciplinar tanto de forma vertical quanto horizontal de conteúdos. Após ter finalizado a Matriz de conteúdos da UTA, os professores escrevem Rotas de Aprendizagem, seguindo a sequência dos temas, cada rota segue uma formatação definida, desenvolvida pelo grupo, que é composta por uma contextualização, apresentação dos conceitos, parte prática e síntese. Como a proposta de se trabalhar a UTA é a interdisciplinaridade, havia a preocupação em não haver sobreposição de conteúdo, assim, surgiu a figura de um quinto professor para fazer o acompanhamento da escrita das Rotas, que foi nominado de "quinto elemento".

Dentro do viés do Blended learning, a intenção dessa mudança pedagógica da IES é possibilitar que os estudantes adquiram as informações (conteúdos) antes das aulas presenciais, pois eles recebem aulas gravadas e disponibilizadas em ambiente virtual de aprendizagem, por meio dos roteiros de estudo, além dos livros em formato físico e digital. Os estudantes também têm acesso à biblioteca virtual, conforme as indicações dos professores, para que complementem os assuntos abordados nas aulas, ou seja, o estudante precisa ter uma postura proativa, engajada no processo, pois, antes de vir para os encontros presenciais, o estudante deve ter lido os capítulos dos livros indicados pelo professor e assistido as vídeos aulas. Assim, durante os encontros presenciais os estudantes aplicam os conceitos teóricos adquiridos previamente.

Segundo Raelin (2007), se os educadores querem preparar pessoas reflexivas, devem prepará-las para sintetizar teoria e prática, que permita ao aluno o papel de sujeito de sua própria aprendizagem, reconhecendo a importância do domínio dos conteúdos para 
a compreensão ampliada do real e mantendo o papel do professor como mediador entre o conhecimento elaborado e o aluno. Assim, o processo de ensino/aprendizagem é direcionado ao estudante, individualmente, no que diz respeito à compreensão e ao processo de recordar em sala de aula, na qual concentram-se mais os processos de aplicar, analisar, avaliar e criar, priorizando as atividades realizadas em equipes.

O acompanhamento dos professores nessa prática, demonstrou um receio inicial, como podemos ver no caso do Professor Alfa, onde ao ser convidado para participar do novo projeto, demonstrou resistência e dúvidas em relação à nova proposta, porém ficou de pensar a respeito, e posteriormente aceitou o desafio. Quando da reunião para a definição dos temas das rotas, cada um dos quatro professores - lembrando que cada UTA tem 4 disciplinas - contribuiu com uma ideia de conteúdo através de suas experiências, com um olhar para as competências que o curso pretendia formar no egresso. Por exemplo, um aluno de Administração precisa aprender a fazer um Balanço Patrimonial? Ou precisa só saber analisar, visto que fazer o Balanço Patrimonial é função do contador.

As reuniões dos professores ocorriam de forma semanal, e esses quatro professores tiveram que pensar em seis grandes temas, que seriam abordados nas rotas de aprendizagem, desceram até a biblioteca e pegaram os livros de autores clássicos das quatro disciplinas, além dos livros base, a coordenação do curso já havia mapeado os principais temas solicitados no Exame Nacional de Desempenho dos Estudantes (ENADE), assim, definiram sobre os temas de cada uma das seis Rotas e os cinco subtemas que compõem cada uma das rotas, de forma que, temas e subtemas passam a ser a ementa das quatro disciplinas da UTA. Portanto quem escreve as ementas são os professores, porém, para que não haja sobreposição de conteúdos, um quinto professor faz a verificação do material escrito por cada um dos quatro professores.

Dessa forma, ao analisar a implantação e desenvolvimento da nova prática de elaboração da UTA, entendemos que os quatro professores, estão inseridos em um processo de mudança, entre o modelo tradicional e um novo modelo. Ao entender como funciona a criação de grades em um preceito tradicional da prática de educação e entender essa nossa proposta, podemos dizer que há os elementos da prática de Schatzki (2012), pois há regras, entendimento prático, teleoafetividade e entendimento geral. Schatzki $(2005,2006,2012)$ apresenta que há regras explícitas, preceitos e instruções que unem as ações dentro de uma prática. Elas especificam o que fazer, conectando tarefas e projetos. Assim, a regra a ser seguida era o olhar para as experiências de mercado, ao ENADE, as DCN do curso de administração e as literaturas clássicas dos temas. 
Ainda, quando em 2014 houve o 'start' para a implantação de uma nova metodologia de educação na IES, o cenário foi marcado por incertezas, inseguranças, angústias e tensão, pois o que Schatzki (2012) chama de "ongoing" da prática deixou de existir, passando a haver o 'breakdown', ou seja, uma ruptura no processo da prática de educação, por parte dos professores, que se reuniam para formação das temáticas da UTA. Os professores ao elaborarem a UTA objetivaram a chegar ao ideal do projeto maior que foi planejado pela Instituição, assim, esses quatro professores desenvolveram a teleoafetividade, que Schatzki (2012) identifica como um dos mecanismos que ligam as ações, tarefas, projetos e eventos em uma prática, ao ter um propósito.

Por fim, a teleoafetividade é verificada quando os quatro professores passaram a se encontrar para trocar experiências vivenciadas para discutir a concepção da matriz de conteúdo. Percebeu-se que havia participação de forma engajada entre os professores, desenvolvendo relações de afetividade, por meio de um conjunto de fins e propósitos que estavam hierarquicamente organizados, assim, os praticantes realizaram ações e projetos específicos, de acordo com os fins e os propósitos do projeto global proposto pela IES. E, A identidade do grupo se constituiu quando desenvolvem o sentido de pertencimento, ao se intitularem como "pioneiros" do método.

\section{CONSIDERAÇÕES FINAIS}

Ao participar da prática diária dos professores, na implantação do projeto por meio da construção da matriz de conteúdo e das rotas de aprendizagem, foi possível verificar que quando houve o 'start' para esse novo projeto, os professores não sabiam como atender ao que foi proposto pela IES. Entre acertos e erros, eles foram ajustando e construindo no ambiente de trabalho, por meio da prática, artefatos que foram considerados mediadores e que possibilitaram a implantação da interdisciplinaridade das quatro disciplinas ofertadas em cada módulo.

Houve também a criação de artefatos, durante a realização da prática dos docentes, possibilitou o desenvolvimento da interdiciplinaridade, tanto no material escrito, como nas atividades desenvolvidas em sala de aula, formando dessa forma as competências necessárias à formação de um administrador.

Ao concluir que novas competências foram desenvolvidas pelo grupo, durante o processo de implantação do projeto, identificamos os elementos que compõem a prática social de Schatzki $(2005,2006)$. Verificamos que outras propostas inovadoras puderam ser implantadas, em um período menor de tempo, demonstrando assim, que o grupo de professores se mobilizou para que o projeto desse certo e construíram o Knowing in 
Practice.

Por fim, ensejamos que esse estudo possa contribuir para os Estudos Baseados na Prática (EBP) possibilitando reflexões futuras sobre a formação continuada do administrador, a fim de formar as competências profissionais necessárias para atender ao contexto organizacional complexo no qual as organizações estão inseridas.

\section{REFERÊNCIAS}

ASSIS, L. B.; PAULA, A. P. P.; BARRETO, R. O.; VIEGAS, G. Estudos de caso no ensino em Administração: O erro construtivo libertador como caminho para inserção da pedagogia crítica. Revista de Administração Mackenzie, v. 14, n. 5, p. 44-73, 2013.

BISPO, M.S. Aprendizagem Organizacional Baseada no Conceito de Prática: Contribuições de Silvi Gherardi. RAM: vol 14 n.6, 2013.

BRASIL. Lei de Diretrizes e Bases da Educação Nacional. Lei 9.394/96. Brasília: Imprensa Oficial, Diário Oficial da União, v. 134, n. 248, 1996.

BRASIL. RESOLUÇÃO № 4, DE 13 DE JULHO DE 2005. Disponível em: <http://portal.mec.gov.br/cne/arquivos/pdf/rces004_05.pdf>. Acesso em 15 jan. 2018.

BRASIL. PARECER № CNE/CES 67/2003, DE 13 DE MARÇO DE 2003. Disponível em: $<$ <ttp://portal.mec.gov.br/cne/arquivos/pdf/CES0067.pdf>. Acesso em 15 jan. 2018.

D’AMBROSIO, Ubiratan. Educação para uma sociedade em transição. Campinas, São Paulo: Papirus, 1999.

DE BARCELLOS, Rebeca de Moraes Ribeiro; DO LIVRAMENTO DELLAGNELO, Eloise Helena; SALIÉS, Gabriel Portela. Universidade, sociedade e formação do administrador: uma reflexão necessária. Administração: Ensino e Pesquisa, v. 12, n. 4, p. 671-696, 2011.

HOBMEIR, E. C. ; ALVES, E. B. ; SCHNEIDER, E. I. ; ROLON, V. E. K. . Blended learning na prática: uso de atividades práticas interdisciplinares como o BMG Canvas para a construção do conhecimento. In: Andreza Regina Lopes da Silva. (Org.). Demandas para a Educação a Distância no Brasil no século XXI. 1ed.Curitiba: Atena Editora, 2017, v. 1, p. 27-28. 
INEP. MEC e Inep divulgam dados do Censo da Educação Superior 2016. Disponívelem:<http://portal.inep.gov.br/artigo/-/asset_publisher/B4AQV9zFY7Bv/conten $\mathrm{t} /$ mec-e-inep-divulgam-dados-do-censo-da-educacao-superior-2016/21206>. Acesso em 15 Mar 2018.

JAPIASSU, Hilton. Interdisciplinaridade e Patologia do saber. Rio de Janeiro: Imago, 1976.

JAIME JUNIOR, Pedro. Pesquisa em organizações: por uma abordagem etnográfica. Civitas-Revista de Ciências Sociais, v. 3, n. 2, 2003.

LAVE, J; WENGER, E. Situated learning. Legitimate peripheral participation.

MORIN. A cabeça bem feita. Repensar a reforma repensar o pensamento. 6 ed., Rio de janeiro: Bertrand Brasil Itda, 2002.

RAELIN, Joseph A. Toward an epistemology of practice. Academic of Management Learning and Education, v.6, n.4, p. 495-519, 2007.

SANDBERG, Jörgen. How do we justify knowledge produced within interpretive approaches?. Organizational research methods, v. 8, n. 1, p. 41-68, 2005.

SCHATZKI, T. R. The site of organizations. Organizations Studies. 26(03):465-484, 2005.

SCHATZKI, T. R. On Organizations as they happen. Organizations Studies. 27(12):1863-1873, 2006.

SCHATZKI, Theodore R. A primer on practices. In: Practice-based education. SensePublishers, 2012. p. 13-26.

[1] Sala de aula invertida

[2] Ensino Combinado; Ensino Hibrido 